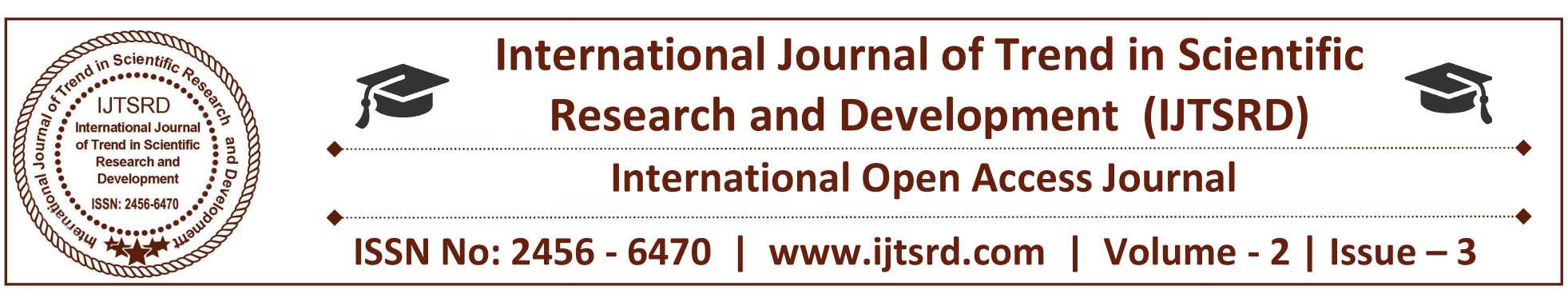

\title{
Integrated Renewable Energy System with the use of Battery Energy Storage
}

\author{
Deepika Dhakad \\ Student, Department of Electrical \\ Engineering, Poornima College of \\ Engineering, Sitapura, \\ Jaipur, Rajasthan, India
}

\author{
Abhishek Maurya \\ Student, Department of Electrical \\ Engineering, Poornima College of \\ Engineering, Sitapura, \\ Jaipur, Rajasthan, India
}

\author{
Raksha Goyal \\ Assistant Professor, Department of \\ Electrical Engineering, Poornima \\ College of Engineering, Sitapura, \\ Jaipur, Rajasthan, India
}

\section{ABSTRACT}

Renewable sources like solar, wind, hydro are green resources of energy. They are environment friendly, freely available and promising power generating sources due to their availability and topological advantages for local power generation. This paper will review the status of power generation through renewable sources, government involvement and study of various battery energy storage technologies. technologies. This paper will try to find performance characteristics of battery storage technologies using Simulink.

Keywords: renewable energy integration, battery technologies, reliability index, off-grid electrification

\section{INTRODUCTION}

The demand for energy is increasing day by day and therefore it cannot be fulfilled by conventional sources of energy. Integrated renewable energy system is a combination of renewable and conventional energy source, it may also combine two or more renewable energy sources that work in standalone or grid connected mode. In order to take benefit of large number of dispersed renewables, integration is a necessity. Integration of renewable energy sources involves integrating in a system any energy resource that naturally regenerates. It allows greater use of cleaner, environmental friendly renewable resources.
India has nearly unelectrified 60,000 villages and has a large potential for integration of renewable energy resources Small-scale implementation of renewable energy systems in the form of micro-wind turbines or photovoltaic installations coupled with energy storage systems provide the ability to supply power to commercial buildings and residential dwellings while offsetting grid consumption. But these renewable resources are weather dependent and may fluctuate with change in weather conditions. For this reason, it will be beneficial to use battery energy storage as we can use stored energy when renewable energy system is not generating power. Battery energy storage has several advantages which are-

- Greater use of generally cleaner and more efficient energy sources.

- Inconsistency in supply due to intermittency of weather conditions.

- For allowing fluctuating renewable energy sources to be as stable as conventional systems.

- To lower electricity costs by purchasing electricity during off-peak periods.

- Provision of backup power for critical loads.

- Improvement of reliability and quality of electricity supply.

This paper gives details about various government projects and policies for promoting the use of 
renewable resources. It also presents comparative study of different battery storage technologies.

\section{GOVERNMENT INVOLVEMENT}

The government has launched several renewable based projects to reduce the dependence on conventional sources of energy. Some of these projects are discussed in detail.

A. The Jawaharlal Nehru National Solar Mission was launched on the 11th January, 2010 by our former Prime Minister, Dr. Manmohan Singh. The Mission has set the ambitious target of deploying 20,000 MW of grid connected solar power by 2022 and aims at reducing the cost of solar power generation in the country through (i) long term policy; (ii) large scale deployment goals; (iii) aggressive $\mathrm{R} \& \mathrm{D}$; and (iv) domestic production of critical raw materials, components and products. It has been envisaged to achieve grid tariff parity by 2022. The objective of the Jawaharlal Nehru National Solar Mission is to establish India as a global leader in solar energy, by creating the policy conditions for its large scale diffusion across the country as quickly as possible. For this purpose, the Mission has adopted a 3-phase approach: the 11th Plan and first year of the 12th Plan (up to 2012-13) has been considered as Phase 1 , the remaining 4 years of the 12th Plan (201317) are included as Phase 2, and the 13th Plan period (2017-22) is envisaged as Phase 3. An evaluation of progress, review of capacity and targets for subsequent phases, based on emerging cost and technology trends, both domestic and global, would be undertaken at the end of each plan period, and mid-term during the 12th and 13th Plans. The first phase of NSM focused on capturing the low hanging options in solar: on promoting off-grid systems to serve rural populations and a modest capacity addition in grid-based systems. This was partly envisaged as a learning experience for the further, ambitious goals. Now, in the second phase, an aggressive capacity ramp-up is targeted. The aim is to create favorable conditions for up-scaled and competitive solar energy penetration in both at the centralized and decentralized levels.

B. On 30 November 2015, the Prime Minister of India Narendra Modi and the Prime Minister of France Francois Hollande launched the Alliance. The ISA is an alliance of 121 solar rich countries lying partially or fully between the Tropic of Cancer and the Tropic of Capricorn, several countries outside of this area are also involved with the organization. The ISA aims to promote and develop solar power amongst its members and has the objective of mobilizing \$1 Trillion dollars of investment by 2030 .

C. The Indian Solar Loan Programme, supported by the United Nations Environment Programme has won the prestigious Energy Globe World award for Sustainability for helping to establish a consumer financing program for solar home power systems. Over the span of three years more than 16,000 solar home systems have been financed through 2,000 bank branches, particularly in rural areas of South India where the electricity grid does not yet extend. Launched in 2003, the Indian Solar Loan Programme was a four-year partnership between UNEP, the UNEP Risoe Centre, and two of India's largest banks, the Canara Bank and Syndicate Bank.

D. A national bioenergy mission was announced to provide 20,000MW biomass power by 2022 .

E. MNRE has announced a wind mission to ramp up installation of wind power in the country.

\section{BATTERY ENERGY STORAGE TECHNOLOGIES}

As these renewable resources are weather dependent and may fluctuate with change in weather conditions. So, we can store energy in these battery storages and can use when renewable energy system is not generating. Some of the most commonly used battery energy storage technologies are discussed with their characteristics.

\subsection{Lead - Acid}

- Low maintenance requirement

- Photovoltaic and micro-wind application

- Low energy density

- Non- environment friendly

- Limited life cycle

\subsection{Nickel Cadmium (NiCd)}

- High energy density

- Longer life cycle

- Low maintenance requirement

- Toxic- heaviness of cadmium 
- High cost

\subsection{Nickel Metal Hydride (NiMH)}

- Compact and lightweight

- Longer life cycle

- Hybrid electric vehicles application

- Environment friendly

- Provide additional capacity

\subsection{Lithium-Ion}

- Highest energy density

- Portable electronics application

- High cost

- Complicated charge management system is represented by a generic function block obtained from the Sim Power Systems toolbox in Simulink.

This PV block shown is suited for when modules are connected in parallel and share the same voltage. The input parameters for this model are PV Voltage, Vpv $(\mathrm{V})$, and Irradiation $(\mathrm{W} / \mathrm{m} 2)$. The module parameters for the PV Module subsystem are: short-circuit current, open-circuit voltage, rated current and rated voltage at maximum power point. The limitation of this model is that it does not take in to account the effect of ambient temperature. The PV Module represented in the above model is a Unisolar US-42 Solar Panel.

The characteristics of the panel are shown below:

- Maximum Power, Pmax: $42 \mathrm{~W}$

- Nominal Voltage: $12 \mathrm{~V}$

- Open Circuit Voltage, Voc: $23.8 \mathrm{~V}$

- Voltage @ MPP, Vmpp: 16.5V

- Current @ MPP, Impp: 2.54A

In figure 1, the lead-ion battery is used for simulation model. We can perform same simulation for other three types of batteries also.

\begin{tabular}{|l|l|l|l|l|}
\hline $\begin{array}{l}\text { Energy } \\
\text { density }\end{array}$ & Low & $\begin{array}{l}\text { Highe } \\
\mathrm{r}\end{array}$ & $\begin{array}{l}\text { Highe } \\
\mathrm{r}\end{array}$ & Highest \\
\hline $\begin{array}{l}\text { Environment } \\
\text { friendly }\end{array}$ & No & No & Yes & Yes \\
\hline Life cycle & $\begin{array}{l}\text { Limite } \\
\text { d }\end{array}$ & $\begin{array}{l}\text { Longe } \\
\text { r }\end{array}$ & $\begin{array}{l}\text { Longe } \\
\text { r }\end{array}$ & Long \\
\hline Maintenance & Low & Low & Low & Low : 2 \\
\hline Cost & Low & High & Low & High \\
\hline
\end{tabular}

Table 1: Comparison of different battery storage technologies

From above table 1 , it is clear that Nickel Metal Hydride (NiMH) battery is the most efficient battery storage technology due to high energy density, longer life cycle and does not affect environment.

\section{BATTERY ASSESSMENT USING SIMULINK}

In this section, technical characteristics of batteries in a photovoltaic system are assessed in a simple manner using MATLAB based Simulink. Fig. 1 presents a straightforward stand-alone photovoltaic system containing a PV module, battery and switched load, replicated using standard Simulink blocks and custom designed function blocks. The battery shown in Fig.1 
International Journal of Trend in Scientific Research and Development (IJTSRD) ISSN: 2456-6470

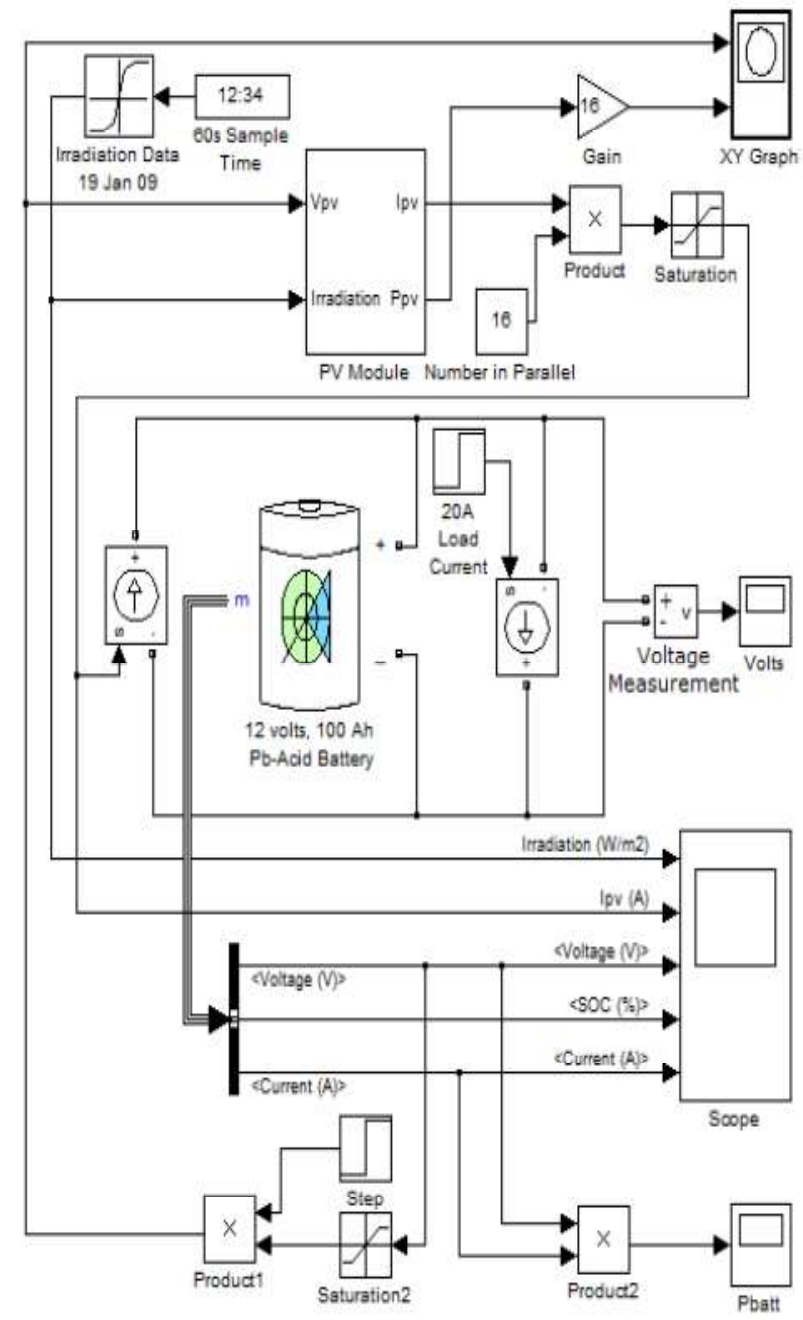

Figure 1: Simulink Model for Stand- Alone PV System

We obtain voltage characteristics and P-V plot for lead-acid, NiCd, NiMH and lithium ion battery using this simulation. From Fig 2, we can see that the rate of increase in voltage of the NiMH and Li-ion battery voltage is significantly higher than that of the $\mathrm{NiCd}$ and lead-acid battery i.e., NiMH and Li-ion batteries reach their nominal voltage faster than the $\mathrm{NiCd}$ and lead-acid batteries. The instantaneous Power-Voltage graphs are plotted for all four types and are shown in Fig. 3.

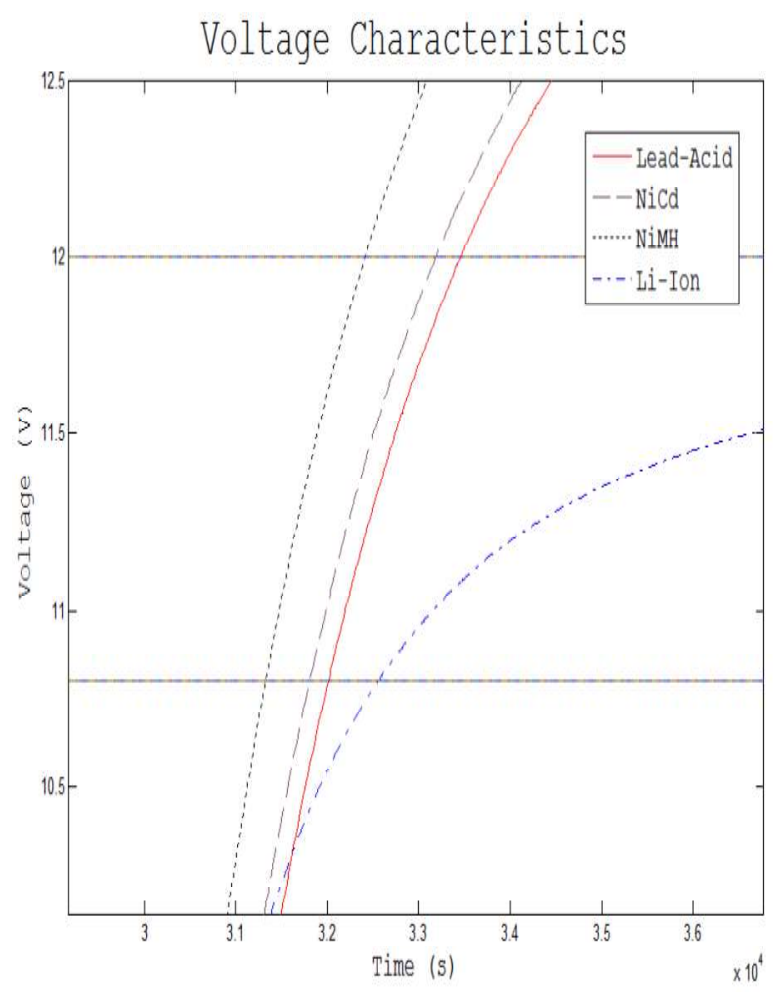

Figure 2: Battery Voltage Characteristics

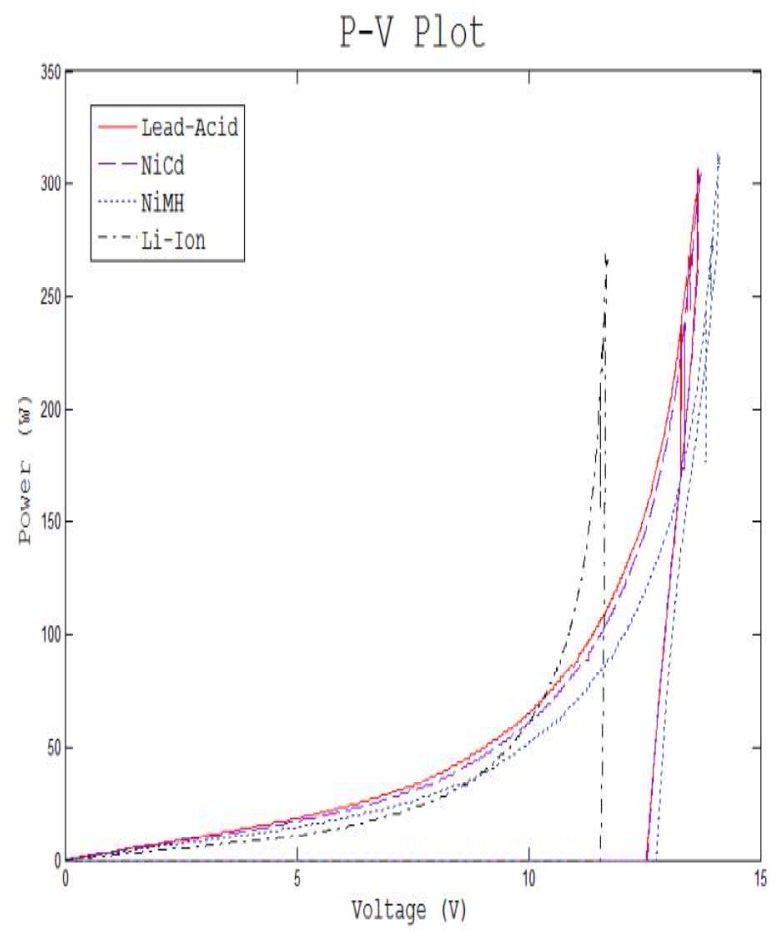

Figure 3: P-V Plot Comparison

The NiMH battery produces more power than all the other batteries by reaching a value of approximately $314 \mathrm{~W}$. Lead-acid battery power characteristics are very similar to that of the NiCd battery as shown in 
Fig. 6. The Li-ion battery power peaks at $270 \mathrm{~W}$ due to its low peak voltage value of $11.7 \mathrm{~V}$.

The values prove that $\mathrm{NiMH}$ and $\mathrm{Li}$-ion batteries appear to reach their nominal voltage from zero SOC more rapidly than the $\mathrm{NiCd}$ and lead-acid batteries (Pb-Acid). The lead-acid battery takes the longest time to reach its nominal voltage. The instantaneous power measured for each battery depended upon its peak voltage measurement. In this assessment, $\mathrm{NiCd}$ and $\mathrm{NiMH}$ batteries provided a high maximum power output measurement.

\section{CONCLUSION}

Energy demand is increasing each year with increase in population. Fossil fuels are getting depleted and cause pollution, carbon emission. So, we need to move towards the use of renewable energy resources. Integrated renewable energy system is making a way for electrification of several villages along with cleaner use of renewable resources. The use of battery storage in renewable energy system improves the system reliability and security. With benefits ranging from greater use of cleaner energy sources to potential cost savings, battery energy storage systems can ensure security and continuity of supply in integration of small scale renewable energy resources. From simulation, we have found that NiMH battery is most efficient technology with highest power generation. $\mathrm{NiMH}$ batteries have the highest potential for development in small-scale renewable energy integration applications provided initial capital costs for this technology are lowered. A high initial capital cost is the main hindrance to use of NiCd batteries.

\section{REFERENCES}

1) Renewable energy in India: current status and future potentials A Kumar, $\mathrm{K}$ Kumar, N Kaushik, S Sharma... - Renewable and ..., 2010 Elsevier

2) Integration of Renewable Energy Sources in future power systems: The role of storage $\mathrm{S}$ Weitemeyer, D Kleinhans, T Vogt, C Agert Renewable Energy, 2015 - Elsevier

3) Minimising emissions and energy wastage by improved industrial processes and integration of renewable energy JJ Klemeš, PS Varbanov, S Pierucci... - Journal of Cleaner ..., 2010 - Elsevier

4) Battery energy storage systems: Assessment for small-scale renewable energy integration NKC Nair, N Garimella - Energy and Buildings, 2010 Elsevier

5) On the progress of renewable energy integration into smart grids in India $\mathrm{S}$ Mukhopadhyay, SK Soonee, R Joshi... - Power and Energy ..., 2012 - ieeexplore.ieee.org

6) Integrating waste and renewable energy to reduce the carbon footprint of locally integrated energy sectors S Perry, J Klemeš, I Bulatov Energy, 2008 - Elsevier

7) Assessment of the battery energy storage systems for small-scale renewable energy integration $\mathrm{N}$ Garimella, NKC Nair - TENCON 2009-2009 IEEE Region 10 .., 2009 - ieeexplore.ieee.org 